\title{
Práticas sustentáveis temperadas por memórias e experiências
}

\author{
Sustainable practices seasoned with memories and \\ experiences
}

Mônica Chaves Abdala ${ }^{1}$

RESUMO: A proposta deste artigo é apresentar uma reflexão sobre a experiência do Festival Igarapé Bem Temperado, entendendo-a como parte do mosaico de culturas e tradições de Minas Gerais, do Brasil e de um conjunto de movimentos para preservação do patrimônio cultural do estado. O reconhecimento de expressões locais, a valorização de experiências e saberes femininos relativos a conhecimentos ancestrais com foco na segurança alimentar, assim como a possibilidade tanto de resgatar identidades como de desenvolvimento econômico sustentável, constituem elementos centrais na análise. Trata-se também de investigar as diferentes formas pelas quais as tradições culinárias são ressignificadas, fazendo sentido para os grupos que as reafirmam, ao mesmo tempo que são manipuladas no bojo da reconstrução permanente do "tradicional e típico" mineiro. Mário de Andrade, Eric Hobsbawm, Carlos Dória e Marcelo Bastos, entre outros autores foram chamados ao diálogo numa tentativa de compreender a dinâmica cultural e política desse jogo de identidades e tradições mineiras.

Palavras-chave: tradições; sustentabilidade; memórias; saberes femininos; comida mineira.
ABSTRACT: The purpose of this article is to present a reflection about the experience of the Igarapé Bem Temperado Festival, understanding it as part of the mosaic of culture and tradition of Minas Gerais, of Brazil and of a group of movements for the preservation of the state cultural heritage. The recognition of local expressions, the valuing of feminine experiences regarding ancestral knowledge focusing on food security, the possibility to rescue identities, as well as the possibility of sustainable economic development are the central elements of the analysis. It is also about investigating the different ways through which the culinary traditions are re-signified, so that it makes sense for the groups who reaffirm them, at the same time they are manipulated at the center of permanent reconstruction of the "typical and traditional" ways of Minas. Mário de Andrade, Eric Hobsbawm, Carlos Dória e Marcelo Bastos, among other authors were called into the dialogue in an attempt to understand the cultural and political dynamics of this game of identity and tradition from Minas Gerais.

Keywords: tradition; sustainability; memory; female knowledge; Minas Gerais food.

1 Doutora em Sociologia pela Faculdade de Filosofia, Letras e Ciências Humanas da Universidade de São Paulo. Professora titular aposentada do Instituto de Ciências Sociais e docente do corpo permanente do Programa de Pós-Craduação em História da Universidade Federal de Uberlândia. 


\section{Introdução}

Ao longo dos anos temos refletido sobre a construção das tradições culinárias mineiras, sua apropriação como pilar central na imagem do estado e as iniciativas sempre renovadas para seu fortalecimento e reafirmação. É possível observar uma espécie de protagonismo de Minas Gerais na permanente articulação de diversos atores com o poder público no que concerne à valorização de sua "cozinha tradicional e típica", visando reforçar sua identidade e sua imagem, assim como seu desenvolvimento econômico.

Alguns dos projetos originados e efetivados no estado tiveram ramificações além de seu território, como ocorre com o Fartura Gastronomia, organizador do Festival de Cultura e Gastronomia de Tiradentes, que realiza expedições gastronômicas em âmbito nacional, com produção de vídeos e livros sobre as cozinhas regionais. Outros se expandem para todo o país, como ocorreu com o Comida di Buteco, que hoje está presente em várias regiões brasileiras. Minas tem seu "dia da gastronomia mineira", sua "semana da gastronomia mineira" e conta com uma Frente de Gastronomia Mineira (FCM). A atuação dos grupos ligados à Frente culminou em leis e pactos que apoiam políticas estaduais destinadas ao "setor de gastronomia", e sua organização tem servido de inspiração para outros estados que procuram adotar modelo semelhante, a exemplo do Ceará'.

A cada ano se avolumam iniciativas como organização de roteiros turísticos, produção de documentários, registros de patrimônios imateriais e de Indicações Geográficas e até mesmo houve participação como tema de samba enredo da escola de samba carioca Salgueiro, no ano de 2015, com base no livro História da arte da cozinha mineira por Dona Lucinha (Nunes; Nunes, 2010). Em dezembro de 2016, o então governador de Minas Cerais, Fernando Pimentel, assinou a Lei 22458 decretando a gastronomia mineira como patrimônio cultural do estado². Entre as inúmeras manifestações estão festivais e feiras gastronômicas que ocorrem com regularidade, assim como participação em eventos internacionais, que se estruturam com o propósito de preservação da tradição e do patrimônio, fomentando o turismo. Nesse contexto, permanece a referência ao que se convencionou considerar "tradicional e típico", resultado de uma elaboração intelectual e política que selecionou determinadas tradições em um amplo e variegado conjunto ${ }^{3}$. No entanto, uma pluralidade de tradições locais vai se revelando.

Documentar essa diversidade que brota no bojo de uma conjuntura de valorização das tradições e de patrimonialização dessas torna-se imprescindível. Diz respeito à reflexão relativa às "materialidades em que a cultura se encarna", assim como à relação estabelecida com o passado

\footnotetext{
1 A respeito do conjunto de iniciativas aqui referidas, ver Abdala (2018).

2 O autor da lei, deputado Agostinho Patrus Filho, expressa a perspectiva de internacionalização da "gastronomia mineira", como se pode notar na citação reproduzida por Byrd (2017): "Today we have in Minas Gerais a gastronomy of vanguard," e "we want gastronomia mineira to be known and appreciated by the entire planet". Ações com esse propósito vinham ocorrendo desde o governo anterior, de Antônio Anastasia, conforme apontamos em nossa recente publicação (Abdala, 2018, p. 195, nota 7).

3 Dória e Bastos (2018, p. 293) consideram haver uma "mineirização da cozinha caipira", característica de um território mais amplo, o que representa um "fenômeno cultural digno de nota", conforme retomaremos no decorrer da discussão.
} 
e com as memórias. E, nesse aspecto, valemo-nos da discussão que Mário de Andrade (2002) efetiva sobre as tradições, entendidas como fontes de legitimidade que as tornam significativas na contemporaneidade, conforme apontam Veloso e Madeira (1999, p. 116). No entender de Andrade, por meio das tradições,

[...] comunicam-se noções de continuidade, estabilidade, venerabilidade. A tradição supõe a ética do sagrado, sendo sua transmissão sempre ritualizada. Decorre daí o interesse de Mário pelos ritos sociais, pelo conjunto da sabedoria coletiva que se expressa em manifestações culturais específicas, as quais, por sua vez, têm vigência porque possuem legitimidade e contemporaneidade. (Veloso; Madeira, 1999, p. 117)

Ainda na esteira de suas considerações relativas às "viagens de descoberta do Brasil", que foram publicadas no livro $O$ turista aprendiz (Andrade, 2002), o autor apresenta sua concepção de tradições "móveis", aquelas que se modificam naturalmente, fazendo sentido no presente, numa espécie de incorporação do passado na atualidade, distinguindo-as daquelas que chamou de “imóveis". Em suas palavras:

Dizem que sou modernista e... paciência! O certo é que jamais neguei as tradições brasileiras, as estudo e procuro continuar a meu modo dentro delas. É incontestável que Gregório de Matos, Dirceu, Álvares de Azevedo, Casimiro de Abreu, Euclides da Cunha, Machado de Assis, Bilac ou Vicente de Carvalho são mestres que dirigem a minha literatura. Eu os imito. O que a gente carece, é distinguir tradição e tradição. Tem tradições móveis e tradições imóveis. Aquelas são úteis, têm importância enorme, a gente as deve conservar talqualmente são porque elas se transformam pelo simples fato da mobilidade que têm. Assim por exemplo a cantiga, a poesia, a dança populares. As tradições imóveis não evoluem por si mesmas. Na infinita maioria dos casos são prejudiciais. Algumas são perfeitamente ridículas que nem a 'carroça' do rei da Inglaterra. Destas a gente só pode aproveitar o espírito, a psicologia e não a forma objetiva. (Andrade, 2002, p. 227)

Nas "viagens de descoberta" e na Missão Folclórica de 1938, quando esteve à frente do Departamento de Cultura de São Paulo, nota-se claramente a busca e descoberta de manifestações e seu efetivo registro, legando-nos a compreensão de que as tradições dizem respeito à forma como os atores sociais constroem suas relações no tempo e no espaço, dando-lhes sentido no seu cotidiano e ressignificando-as. Esse é um fator importante a ser considerado, ainda que sejam alvos privilegiados de construção intelectual e política.

Hobsbawm (1984), em seu estudo sobre tradições inventadas, em certo momento questiona: "até que ponto elas [tradições] serão manipuláveis?". Também ele reconhece que elas devem ser descobertas, e que são estreitos os limites para sua "modelação". No seu dizer:

[...] parece claro que os exemplos mais bem sucedidos de manipulação são aqueles que exploram práticas claramente oriundas de uma necessidade sentida - não necessariamente compreendida de todo - por determinados grupos. [...] Os gostos e as modas, especialmente na área do divertimento popular, podem ser "criados" apenas dentro de limites bastante estreitos; têm de ser descobertos antes de serem explorados e modelados. (Hobsbawm, 1984, pp. 315-316) 
Nessa perspectiva de descobertas e explorações, buscamos as inúmeras expressões locais que compõem o mosaico das tradições culinárias em Minas Gerais. Uma vez mais, é Mário de Andrade que nos inspira nessa busca, posto que, como bem expressam Madeira e Veloso, ele propõe uma valorização do passado como "fonte de conhecimento apenas na medida em que produz inspiração para o desvendamento de tradições, cujo conhecimento abre possibilidades de futuro" (Veloso; Madeira, 1999, p. 115).

\section{O Festival Igarapé Bem Temperado}

Uma experiência em particularatraiu nossa atenção devido aos aspectose conhecimentos que propiciou durante suas treze edições: o festival Igarapé Bem Temperado (IBT). A questão norteadora ao analisá-la retoma, de certo modo, a proposta de Andrade acima esboçada: como a documentação de memórias abriu e ainda abre possibilidades de futuro? E como faz sentido no presente?

Concordamos com Dória (2018) quando este afirma que a tradição tem seu valor se nos possibilita um repertório no presente, com descobertas renovadas que nos surpreendam a partir da experiência vivida. Nesse sentido, é inspiradora sua reflexão sobre a "ressurgência" de sabores nos pratos do restaurante Jiquitaia, cujo proprietário é coautor do livro A culinária caipira da Paulistânia. Para Dória,

[...] o valor presente da tradição não está na sua permanência como coisa artificialmente viva, tombada como patrimônio imaterial, mas sim como repertório de sabores aos quais se possa recorrer para trazer graça ao que cozinhamos hoje. (Dória, 2018, p. 12)

Além disso, foi instigante pensar a problemática levantada pelo idealizador do evento, Carlos Oliveira Stan: trazer à tona o reconhecimento de uma cozinha caipira "de raiz", por muito tempo invisibilizada. No esteio da visibilidade pretendida, um projeto que envolveu reprodução de saberes e de cultivos, integrando as memórias do passado no presente, produzindo sustentabilidade, segurança alimentar, transformando a vida de mestras, mestres ${ }^{4}$ e suas famílias, assim como a própria sociedade envolvente.

Em nossa correspondência, Stan explicita sua proposta:

Com esta escolha institucionalizada da culinária para representar o Estado, foi omitida uma diversidade fabulosa da cozinha existente no Estado. Nosso exercício exploratório sobre a permanência de hábitos e costumes da cozinha de raiz caipira, ainda existente no município de Igarapé, Minas Gerais, tentará lançar luzes na direção de certas

\footnotetext{
4 Em relação ao título de mestras e mestres, tudo indica que a inspiração veio da referência a mestres de saberes da cultura popular, pelo Instituto do Patrimônio Histórico e Artístico Nacional (Iphan). Conforme Aguiar (2018, p. 102), citando Stan: "Em 2005 mesmo eu lembro que eu fui no lançamento dum, dum projeto do governo federal, e na época o ministro era o Gilberto Gil, parece, e naquela época tava muito em voga a questão da valorização dos mestres dos saberes e tal. Eu acho que nesse meio que eu vô trabalhando essa, essa parte aí [...] (comunicação por áudio via WhatsApp, mai. 2018)". Vale notar que na publicação do Iphan, em sua terceira edição revista e atualizada (2012, p. 33), se pode ler: "No nosso cotidiano também podemos promover a preservação desse patrimônio: [...] procurar conhecer e valorizar nossos mestres e artistas locais".
} 
características da cozinha mineira que de certa forma esteve relegada por muitos anos a invisibilidade [...] Tentaremos aqui apontar o foco para um tipo de comida dos menos abastados. A comida do sujeito intitulado caipira, comida denominada pelos próprios sujeitos investigados como: "Comida de gente pobre".

O Festival ocorreu de 2005 a $2017^{6}$. No entanto, nosso contato se iniciou em 2014, quando participamos do evento inaugurando um ciclo de palestras e seminários que se repetiria nos anos seguintes. Foi originado da pesquisa Retratos e história, do estudante de ciências sociais Carlos Oliveira Stan e da historiadora Cássia Rezende Coelho, visando ao registro de memórias da cidade de Igarapé, na região metropolitana de Belo Horizonte, recorrendo a histórias de vida de pessoas idosas. A partir dos relatos, a dupla detectou uma ênfase nas lembranças relativas aos quintais e aos hábitos alimentares, convidando as senhoras a fazer uma exposição de suas receitas em um evento realizado em uma escola da cidade. Desde então, o festival cresceu e tornou-se um grande acontecimento e, para acolher o numeroso público que passou a frequentá-lo em seus quatro dias de duração, o evento começou a ser realizado na praça principal e em grandes espaços. A esse respeito, Aguiar relata:

Nos primeiros dois anos teve lugar na Escola Estadual Professora Maria de Magalhães [...] e a partir de 2007 na Praça Miguel Henriques da Silva, no centro da cidade. O evento de culminância do IBT foi crescendo e se formatando aos poucos. Incialmente com uma noite de degustação na escola, com três finalistas, formato de concurso e que reuniu público de trezentas pessoas. Em 2016, chegou a reunir cerca de trinta mil pessoas na praça, em quatro dias de duração [...]. (Aguiar, 2018, p. 81)

As atividades sempre foram abertas ao público e protagonizadas por senhoras com mais de 60 anos, as mestras. Com o tempo, alguns homens - os mestres - também passaram a participar do evento, acompanhando as esposas e mães, assim como atuando na construção do forno de barro a lenha para os dias do festival. A presença de respeitados chefs na realização de aulas show com as mestras e nas oficinas com crianças propiciou troca de saberes, influenciando na concepção e apresentação dos pratos. Essa troca propicia diferentes olhares. Se de um ângulo ocorre o que Aguiar (2018) considerou uma "gastronomização" da comida de quintal e uma espécie de "espetacularização", de outro ângulo é característica de uma tendência de valorização de saberes e práticas tradicionais, umaverdadeira busca das raízes que contribui para a permanência e ressignificação das tradições culinárias.

5 Correspondência trocada por e-mail com Stan, em 8 mar. 2014. Em mensagem recente (8 nov. 2018), ele retomou essa questão e acrescentou: "Desde o início a culinária de origem caipira é o norte do festival". E, reiterando análise de Carlos Dória e Marcelo Bastos, cita os autores: "[...] não deixa de ser curioso que quase toda a produção culinário-literária mineira ou paulista publicada até hoje sobre cozinha caipira não se refira a ela nesses termos" (Dória; Bastos, 2018, p. 308).

6 A partir de 2016, a prefeitura rompeu a parceria com o grupo organizador do IBT, promovendo seu próprio festival, no mesmo formato, mesmo local e data em que o evento foi realizado durante suas onze edições anteriores. Protagonizando um claro jogo de poder para capitalizar política e economicamente o acontecimento que se tornou referência para o turismo e economia local, a prefeitura captou patrocinadores, entrou na disputa por verbas decorrentes de editais estaduais, afetando as bases de sustentação e apoio do IBT, o que culminou com a impossibilidade de uma $14^{\mathrm{a}}$. edição em 2018 
Desde sua quarta edição, publicações de catálogos ou livros de receitas, com imagens bem cuidadas, trouxeram um pouco da história dessas personagens, recuperando e recriando quitutes e modos de fazer. O evento nunca se limitou à semana de sua realização, havendo ações e preparativos no decorrer do ano. Além disso, várias das participantes e seus familiares abriram negócios próprios ou passaram a ter suas preparações requisitadas fora do período do festival.

A trajetória que levou ao IBT abrange dimensões como identidade, tradição, patrimônio e memória, valorização da cidade com a divulgação de suas práticas culturais e fortalecimento da economia local. Nos quintais e nas cozinhas das mestras, desvelaram-se memórias e experiências de vida de mais de meio século de existência; estas, por sua vez, tornaram-se fonte de trabalho e de renda, uma vez que o sucesso do evento despertou o interesse de gerações mais novas, que foram incorporadas por meio de uma seleção, assim como atraiu a participação de familiares de várias idades e de ambos os sexos ${ }^{7}$. Além do aspecto econômico e social, essa participação atesta singular investimento na preservação de memórias, saberes e ressignificação das tradições.

Um aspecto relevante do festival diz respeito à forma como são considerados os saberes e as experiências das pessoas idosas. Estas, muitas vezes, são criticadas na sociedade atual pela lentidão e tratadas com impaciência. Não é raro ver seus conhecimentos e experiências apontados como ultrapassados ou mesmo vê-las equiparadas a crianças, infantilizadas. Também não é pouco comum ouvirmos queixas de solidão, e por vezes admitirem resignadamente que "o mundo é dos jovens", que "já tiveram sua vez e seu tempo" ou ainda afirmarem que "idosos só dão trabalho", como observa Ecléa Bosi (1983), em seu livro Memória e sociedade. No Igarapé Bem Temperado, "dar trabalho" adquiriu novo sentido, pois as mestras propiciam emprego, renda e oportunidades aos jovens, aos familiares, às novas gerações. Dão exemplos de vida ao transformarem suas memórias e seus saberes em trabalho pleno de realizações. O relato de Aguiar a partir das entrevistas com as mestras corrobora essa percepção:

Essas transformações se davam em diversas esferas de suas vidas, emocional, social, familiar, econômica, contribuindo até mesmo para a saúde física. Segundo contam as mestras, suas histórias e saberes até a criação do IBT não despertavam grande interesse na família e na sociedade, o que fazia com que se sentissem sem utilidade, ultrapassadas, "esperando a morte chegar". A repercussão do IBT faz com que elas sejam conhecidas "mundialmente", como contou mestra Maria do Sindicato, e com que o seu saber seja algo de que possam se orgulhar e transmitir adiante. (Aguiar, 2018, p.107)

O reconhecimento e a valorização de saberes propiciaram investimentos por parte das mestras e dos seus familiares, ocorrendo o que já havíamos notado em outras situações, tanto em Minas Cerais como em Coiás. Nestas situações, o aprendizado cotidiano feminino, característico do ambiente doméstico, passa a possibilitar um "ganha pão", a exemplo de feiras de pequenos

$7 \quad$ Numerosos e diversificados atores participam do evento, com diferentes trajetórias e interesses, como aponta Aguiar: "Nesta breve apresentação de suas características, é possível perceber diferentes subgrupos - mestras, cozinheiras(os) das novas gerações, familiares, organizadores e instituições, e em cada um deles existem diversas diferenças internas, muitos interesses, motivações e compreensões sobre o que é o IBT e conflitos" (2018, p. 16). 
produtores, do pequeno comércio de doces e das chamadas "quitandas caseiras" ${ }^{8}$, assim como de pequenos restaurantes abertos nas próprias residências. São numerosos os casos de mulheres, mas também há presença de homens nessas atividades, que fornecem produtos artesanais para mercados, supermercados, ou abrem pequenas lojas para vendê-los. A base desse comércio normalmente é constituída pelas receitas de família e pelo saber fazer feminino reproduzidos durante gerações.

No âmbito do trabalho com alimentos, é possível observar esse fato em outros espaços e momentos da história. As mères de Lyon, na França, se tornaram referência quando, na primeira metade do século XX, abriram suas casas para servir uma comida caseira, bem feita, saudável, valorizando a simplicidade e os produtos locais, atraindo a atenção de importantes críticos gastronômicos da época, como também os turistas (Collaço, 2009, pp. 148-149).

O estudo de Collaço (2012) sobre as cantinas italianas em São Paulo, na primeira metade do século XX, também aponta semelhanças com esse processo, tanto no que concerne ao trabalho fundado no saber feminino e na mão de obra familiar, quanto na perspectiva de reafirmação de laços identitários. No entanto, no caso em questão, uma vez superadas as difíceis condições da chegada ao Brasil, os homens assumiram a frente dos negócios e as mulheres retornaram ao lar - o que não ocorre na experiência do IBT ${ }^{9}$.

Outro ponto a ser considerado, como avaliou Stan, é que a resistência inicial em preparar e divulgar "comida de gente pobre", "comida de gente boba", deu lugar ao sentimento de pertença:

E nos relatos delas até hoje, né, quando a gente conversa, elas relatam com muito... Isso é muito importante pra elas, né? É um patrimônio grandioso ali, que faz bem pra elas. Que... na verdade também a gente pode entender isso como uma pertença, né? Que faz com que elas pertençam a algo, né? [...] algo que ligue elas a uma comunidade, que faz sentido, que transforma eles em iguais, e também em diferentes, é claro, que uns gostam de umas coisas outros não, uns tiveram acesso a uma coisa, outra não. Uma coisa assim que eu observei muito, esse relato vem cheio de vontade de continuar tendo essas experiências e cheio de emoção. Que é o motivador da continuidade disso, né?'º

8 Em Minas são chamadas quitandas: bolos, biscoitos, roscas, pães de queijo, broas, bolachas, entre outras. Os estabelecimentos que se especializam na venda dessas iguarias recebem o nome de "Quitandas Caseiras".

9 De acordo com Collaço: "Estas [cantinas] se assentaram no trabalho familiar, conhecimento doméstico de receitas que, além disso, reuniam um caráter rural [...] A clientela inicialmente era de paisani, imigrantes italianos que trabalhavam e moravam proximamente e representou uma forma de incrementar o orçamento doméstico. [...] A comida [...] tinha como principal característica o preparo feito pelas mulheres, principais encarregadas de preparar as refeições, servidas pelos maridos e filhos aos comensais distribuídos em mesas de aparência rústica, muitas vezes espalhadas pela calçada." (Collaço, 2012, pp. 69-70). Ao se profissionalizarem e se tornarem restaurantes de cozinha mais sofisticada, no entanto, "apagam" a presença feminina e são assumidas pelos homens. As mulheres ficam circunscritas ao universo doméstico, mas mantêm uma presença simbólica, "[...] mencionadas com frequência como bastiões da tradição, da família e da boa comida” (Idem) 


\section{"Comida de gente pobre", "comida de gente boba"}

A comida recuperada das histórias e lembranças, que se tornou carro-chefe do IBT, pode ser considerada uma "comida de quintal". Sua base é o angu de fubá ou de milho, com predomínio do fubán", acompanhado de um cozido de verduras da horta ou do quintal, e sempre que possível contendo uma carne, em geral de porco, frango ou galinha, que são os guisadinhos. O feijão de caldo também é muito presente como acompanhamento na cozinha doméstica, mas perde espaço nos pratos do festival, assim como ocorre com a pimenta, devido à necessidade de adequação no que se refere à diferenciação entre cozinhar "pros de casa" e "prosotros", como aponta Aguiar:

A tradição de Igarapé assemelha-se à de diversas cidades e regiões de Minas Gerais. Pratos fartos, sempre acompanhados de arroz, feijão, farinha de milho ou mandioca. Acostumadas(os) à dinâmica de fazer comida "pros de casa", numa lógica não comercial e de degustação de várias opções, as (os) participantes encontraram e ainda encontram muitas dificuldades em adequar os tamanhos e apresentações das porções, bem como a retirada do arroz e feijão como ingredientes compulsórios em todos os pratos. (Aguiar, 2018, p. 133)

À medida que restauram as culturas de quintais, uma série de plantas que por muito tempo estiveram ausentes das mesas retornam à cena. Muitas delas são hoje conhecidas como PANCs ${ }^{12}$, plantas alimentícias não convencionais. Reavivar o hábito de consumo dessas verduras vai ao encontro de movimentos de revitalização da pequena produção e da preocupação com a soberania e a segurança alimentar, assim como com a saúde que o alimento orgânico propicia. E o que é importante, concerne à confiança que o cultivo e o consumo desses alimentos trazem. Como apontam Santos e Menasche: "Em um contexto em que observamos crescente desconfiança da origem dos alimentos, os produtos alimentares tradicionais tornam-se fundamentais para identificação da origem e manutenção da cultura" (2015, p. 1).

É necessário considerar a importância de movimentos como o slow food, apoiando a pequena produção sem agrotóxicos, que se espraiou por todo o planeta, promovendo o alimento "bom, limpo e justo", recuperando cultivares e alimentos tradicionais; como também aqueles que propõem reconhecimento de indicação geográfica, de singularidades associadas ao território, uma vez que ambos contribuíram para esse momento de recuperação e divulgação de saberes e práticas por muito tempo relegadas ao cotidiano de pessoas desfavorecidas. No que concerne a essa "popularização das PANCs", Marcelo Corrêa Bastos atenta também para fatores como a difusão da alta gastronomia que as incorpora, o crescimento do vegetarianismo e a divulgação na mídia por 
meio de "gurus populares da alimentação natural e nutricionistas ligados à agricultura familiar" (2018, p. 24), entre outros.

São interessantes as observações de Bastos quanto à conjuntura que, "por mais paradoxal que possa parecer", aproxima cozinhas ancestrais, como a caipira tratada em seu livro, e modas das "vanguardas gastronômicas" (2018, p. 21). No entender do autor,

a alimentação como uma atividade essencialmente agrícola, noção incorporada por movimentos gastronômicos de ponta, como o locavorismo, e a consequente valorização do terroir descortinam ingredientes, produtos e modos de produção que haviam sido soterrados por práticas agrícolas modernas e demandas comerciais homogeneizadas. A proliferação de PANCS [...], por exemplo, parece um caminho sem volta. [...] Hortaliças que se tornaram raras, como bertalha, dente-de-leão e serralha, começam voltar às feiras e mercados [...]. (Bastos, 2018, p. 21-22)

Nesse quadro, a reflexão nos conduz ao que poderíamos considerar "caminhos cruzados de um mesmo tempo", parafraseando Maria Clara Machado (1998), uma vez que se cruzam diferentes movimentos e possibilidades de análise. De um lado, ao dar visibilidade a costumes que ficaram excluídos na construção da culinária "tradicional e típica mineira" e, desse modo, reconhecer uma pluralidade de tradições locais, nesse movimento, a associação entre mineiro e cozinha não parece ameaçada, mas reforçada no bojo de um conjunto de iniciativas que a ressignificam, como afirmamos anteriormente, atualizando-a e dando sentido. E na medida mesma que se revela o local, nota-se que sua expressão se dá na relação com um movimento global que coloca na ordem do dia pautas de soberania e segurança alimentar, sustentabilidade, locavorismo e políticas de patrimonialização.

De outro lado, análises como as de Dória e Bastos procuram se "libertar" das representações políticas que recortam estados "criando a ilusão de que cada um deles tenha uma culinária típica e singular" (Dória; Bastos, 2018, p. 44). Nessa perspectiva, é possível desvelar o que há em comum na formação histórica de uma vasta área do país e que pode ser observado em especial nos costumes alimentares da região nomeada pelos autores de Paulistânia ${ }^{13}$. De modo um tanto sintético, considerando-se a riqueza da discussão efetivada, poder-se-ia afirmar que a culinária dessa região, a caipira, tem como base a agricultura de subsistência de componentes nativos da cultura guarani, como milho, abóbora, feijão, acrescida de galinhas e porcos criados à base de milho, guardadas as diferenças decorrentes da diversidade da flora, da fauna e de razões históricas. No dizer dos autores,

Embora não haja grandes diferenças entre a culinária dos lugares que se tornam, na República, os estados onde a comida caipira se desenvolveu, talvez o leitor atento seja tomado, às vezes, de surpresa. Andando por cidades do Vale do Paraíba, como Taubaté, não será difícil encontrar restaurantes que oferecem como atrativo a cozinha mineira. Isso porque muito do que estamos considerando aqui a culinária da Paulistânia, a 
cozinha caipira, é conhecido usualmente como cozinha mineira. De fato, houve uma mineirização da cozinha caipira, o que é um fenômeno cultural digno de nota. (Dória; Bastos, 2018, p. 293)

Desse modo, como já apontado anteriormente, quando se observa a produção literária mineira e paulista sobre culinária regional, os autores se surpreendem com o fato de que não haja referências à cozinha caipira nesses termos (Dória; Bastos, 2018, p. 308). Além disso, como se depreende da citação acima, apontam uma construção da culinária mineira fundada em elementos de uma história alimentar relativa a um território que extrapola as fronteiras do estado, havendo uma "mineirização da cozinha caipira".

Nas manifestações e publicações dos organizadores do IBT, Carlos Oliveira Stan e Letícia Aguiar, está presente a menção à "culinária caipira" à medida que reconhecem sua origem e referência ao universo rural, assim como procuram dar visibilidade a hábitos e tradições locais que foram, de certa forma, excluídos do que se convencionou como "cozinha tradicional e típica mineira"14. No entanto, ambos não ignoram em suas análises o quanto a trajetória desse festival se relaciona à construção de um patrimônio gastronômico do estado e termina por participar de uma "narrativa identitária" a partir da comida, como expressou Stan.

É inegável o jogo cultural e político que envolve a elaboração de tradições e o caso da culinária mineira é exemplar pelo protagonismo e mobilização que representa. Todavia, como já mencionamos, inspiradas em Mário de Andrade e Hobsbawm, são estreitos os limites para sua "modelação". Trata-se de tradições "móveis", "têm vigência porque possuem legitimidade e contemporaneidade", fazendo sentido para os grupos que as reafirmam. No contexto aqui analisado, tudo indica que a identificação e a menção à culinária caipira serão incorporadas ao conjunto do que é entendido como "típico mineiro", ampliando seu repertório, ressignificando-o e atualizando-o.

Ao concluir, voltamos a atenção para algumas visões de diferentes atores que participam desse verdadeiro jogo de identidades e tradições mineiras. Para os grupos que se estruturam por meio de projetos e frentes reunindo parte de estudiosos, profissionais da gastronomia, empresários, políticos em defesa da consolidação e divulgação da "gastronomia mineira"15 interessa prioritariamente a possibilidade tanto de resgatar identidades como de sua associação ao desenvolvimento econômico. O chef Eduardo Avelar, que tem sido referência à frente desses projetos e movimentos, quando incitado a esse debate, pondera que ocorre em Minas o mesmo que em numerosos casos na história. Ele nos lembra inclusive o exemplo do hambúrguer, em que a culinária originada em uma região se expande, extrapola fronteiras nacionais, e se torna símbolo em outro território ${ }^{16}$.

14 É fato que os dois mencionam culinária caipira nos termos aqui esboçados, entretanto, ao passo que Stan incorpora essa categoria em suas análises, em sua dissertação, Aguiar (2018) se refere à "culinária de quintal”. De todo modo, independente de como é nomeada, como se pode notar, os guisadinhos com angu têm a mesma base da culinária caipira referida por Dória e Bastos (2018).

15 Cf. Abdala (2018) 
As pessoas que formam a base de toda a cadeia produtiva, organizadas ou não em comunidades e associações, são protagonistas de suas histórias e dão exemplo de experiências de sustentabilidade, como ocorre com o IBT. Para elas importa a valorização de seus saberes ancestrais e a ressignificação de suas experiências que se tornam reconhecidas possibilitando novos arranjos de suas vidas e, sobretudo, geração de renda. Nesse processo conquistam visibilidade ao mesmo tempo que se fortalecem identidades e economias locais que, não raras vezes, são articuladas à imagem regional por força de estratégias nos campos da cultura e da política.

Compreender esse investimento de diferentes setores na chamada "gastronomia mineira", do ponto de vista acadêmico, tem nos impulsionado a retomar a construção histórica que fez da cozinha elemento central em diferentes formas de sociabilidade, compreender como se estrutura um mito da mineiridade e como a cozinha contribui nessa estruturação, e também investigar como as tradições são manipuladas e ressignificadas no bojo da reconstrução permanente dessa mineiridade. Ao refletirmos sobre o fato de que alguns dos pratos símbolos da cozinha mineira não são exclusivos de Minas Gerais, como o próprio Frieiro (1982) já assinalara, é possível perceber que em torno de hábitos alimentares estabelecemos rituais de sociabilidade que, ao longo da história, contribuíram para formatar o sentido de referência identitária e a imagem de Minas associada à cozinha e à hospitalidade ${ }^{17}$.

São necessárias investigações históricas que contribuam para desvelar os contextos regionais ou locais em que um grande mosaico de experiências vai se articulando e fazendo sentido. É fundamental aprofundar e ampliar a discussão, trazendo novas perspectivas, como o fazem Byrd, Dória e Bastos. No entanto, há um vasto caminho a percorrer no que tange à incorporação de uma comida caipira em termos do reconhecimento de uma história alimentar que extrapola as fronteiras do estado, como sinaliza o estudo "quase arqueológico"18 de Dória e Bastos (2018). Um diálogo entre pesquisas fundadas na compreensão da história e das estratégias culturais e políticas de construção identitária, de um lado, e visões de grupos ativos que se constituem em vários níveis da sociedade em defesa da afirmação de um patrimônio culinário regional, tendo em foco o turismo e o desenvolvimento econômico, de outro, tende a ser um processo lento e demorado.

\footnotetext{
sido nomeado de hamburg steak. Hoje tem sua imagem relacionada a hábitos alimentares da América do Norte e, a partir dos Estados Unidos, ganhou o mundo na forma de sanduíche. A respeito dessa versão para a história do hambúrguer ver: "O Hambúrguer". Superlnteressante, 31 out. 2016. Disponível em:<https://super.abril.com.br/comportamento/o-hamburguer/>. Acesso em 1 nov. 2018.

17 A respeito dessa discussão, ver Abdala (2007) e Abdala (2018). Consultar também Byrd (2017), Dória e Bastos (2018), que apresentam importantes discussões sobre construção das identidades brasileira e regional mineira. Quanto ao mito da mineiridade, ver Arruda (1990)

18 Apropriamo-nos aqui da expressão utilizada por Luiza Fecarotta (2018), reconhecendo a amplitude e o aprofundamento da discussão efetivada no livro de Dória e Bastos, da qual exploramos apenas um pequeno recorte.
} 


\section{Referências}

ABDALA, Mônica Chaves. Tradições bem temperadas. In: PIRES, Maria do Carmo; MACALHÃES, Sônia Maria de (Orgs.). A cozinha brasileira e o patrimônio cultural: história, hospitalidade e turismo. Curitiba: Editora Prisma, 2018.

Comida e gênero: reflexão sobre mulheres e cozinha em Minas Cerais. In: MAIA, Cláudia; PUCA, Vera Lúcia (Orgs.). História das mulheres e do gênero em Minas Gerais. Florianópolis: Editora Mulheres, 2015.

Receita de mineiridade: a cozinha e a construção da imagem do mineiro. 2 ed. Uberlândia: Edufu, 2007.

ACUIAR, Letícia Cabral. De "comida de gente pobre" à gastronomia: a trajetória da "comida de quintal" através do festival Igarapé Bem Temperado. Dissertação (Mestrado em Ciências Sociais) - Programa de Pós-Graduação em Ciências Sociais da Pontifícia Universidade Católica de Minas Gerais. Belo Horizonte, 2018.

ANDRADE, Mário de. O turista aprendiz. Belo Horizonte: Editora Itatiaia, 2002.

ARRUDA, Maria Arminda do N. Mitologia da mineiridade. O imaginário mineiro na vida política e cultural do Brasil. São Paulo: Brasiliense, 1990.

BASTOS, Marcelo Corrêa. Identidade caipira. In: DÓRIA, Carlos Alberto; BASTOS, Marcelo Corrêa. A culinária caipira da Paulistânia: a história e as receitas de um modo antigo de comer. São Paulo: Três Estrelas, 2018.

BOSI, Ecléa. Memória e sociedade: lembranças de velhos. São Paulo: T. A. Queiroz, 1983.

BYRD, Steven. Comida mineira: a "cultural patrimony" of Brazil. Global Food History, v. 4, n. 1, pp. 7897, nov. 2017.

COLLAÇO, Janine Helfst Leicht. Restaurantes e trabalho entre famílias italianas: a variedade da experiência étnica. In: MACHADO, Maria Clara Tomaz; RAMOS, Alcides Freire (Orgs.). Nas veredas da história: itinerários e transversalidades da cultura. Uberlândia: Edufu, 2012. Sabores e memórias: cozinha italiana e construção identitária em São Paulo. Tese (Doutorado em Antropologia Social) - Faculdade de Filosofia, Letras e Ciências Humanas da Universidade de São Paulo. São Paulo, 2009.

DÓRIA, Carlos Alberto. Se verá que o Brasil não é longe daqui. In: DÓRIA, Carlos Alberto; BASTOS, Marcelo Corrêa. A culinária caipira da Paulistânia: a história e as receitas de um modo antigo de comer. São Paulo: Três Estrelas, 2018.

; BASTOS, Marcelo Corrêa. A culinária caipira da Paulistânia: a história e as receitas de um modo antigo de comer. São Paulo: Três Estrelas, 2018.

FECAROTTA, Luiza. Obra faz investigação quase arqueológica da cozinha paulista. Folha de S. Paulo, São Paulo, 14 out. 2018.

FRIEIRO, Eduardo. Feijão, angu e couve. Ensaio sobre a comida dos mineiros. Belo Horizonte: Editora Itatiaia; São Paulo: Edusp, 1982.

HOBSBAWM, Eric; RANCER, Terence (Orgs.). Ainvenção das tradições. Rio de Janeiro: Paze Terra, 1984. 
INSTITUTO do Patrimônio Histórico e Artístico Nacional (Iphan). Patrimônio cultural imaterial: para saber mais. 3. ed. Brasília: Iphan, 2012.

MACHADO, Maria Clara Tomaz. Cultura popular e desenvolvimentismo em Minas Gerais: caminhos cruzados de um mesmo tempo (1950-1985). Tese (Doutorado em História Social) - Faculdade de Filosofia, Letras e Ciências Humanas da Universidade de São Paulo. São Paulo, 1998.

MENASCHE, Renata; SANTOS, Jaqueline Sgarbi. Valorização de produtos alimentares tradicionais: os usos das indicações geográficas no contexto brasileiro. Cuadernos de Desarrollo Rural, Bogotá, v. 12, n. 75, pp. 11-30, 2015. Disponível em: <http://dx.doi. org/10.11144/Javeriana. cdr12-75.vpat>. Acesso em: nov. 2017.

NUNES, Maria Lucia Clementino; NUNES, Marcia Clementino. História da arte da cozinha mineira por Dona Lucinha. São Paulo: Larousse do Brasil, 2010.

VELOSO, Mariza; MADEIRA, Angélica. Leituras brasileiras: itinerários no pensamento social e na literatura. Rio de Janeiro: Paz e Terra, 1999. 